\title{
Priority Identification for Improving Product Quality as Marketing Strategy
}

\author{
Mugiono Mugiono ${ }^{1}$, Sirajuddin Omsa ${ }^{2,}$, Marjam Desma Rahadhini $^{3}$, Nur Hilal ${ }^{4}$ \\ ${ }^{1}$ Department of Management, Economics and Business Faculty, Brawijaya University, Malang, Indonesia \\ ${ }^{2}$ Department of Accounting, State Polytechnic of Ujung Pandang, Makassar, Indonesia \\ ${ }^{3}$ Department of Management, Economic Faculty, Slamet Riyadi University, Surakarta, Indonesia \\ ${ }^{4}$ Department of Management, Panca Bhakti Institute of Economic Science, Palu, Indonesia
}

Email address:

sirajud_om@yahoo.com(S. Omsa)

${ }^{*}$ Corresponding author

\section{To cite this article:}

Mugiono Mugiono, Sirajuddin Omsa, Marjam Desma Rahadhini, Nur Hilal. Priority Identification for Improving Product Quality as Marketing Strategy. American Journal of Theoretical and Applied Business. Vol. 4, No. 2, 2018, pp. 37-43.

doi: 10.11648/j.ajtab.20180402.11

Received: February 13, 2018; Accepted: April 8, 2018; Published: May 17, 2018

\begin{abstract}
This study aims to produce an outcome of a draft policy to improve the quality of fish nugget made by Melati Business Group (MBG) in Makassar City. By Implementing the suggested policy, it is expected not only can improve the quality of fish nuggets, but also may increase customer buying interest, as well as increase income and welfare of its members. The draft of policy regarding service quality improvement is made by PFI (Priorities for Improvement) analysis method, using gap analysis method to 10 (ten) product quality attributes that have been identified. In addition, mapping is done by using Cartesian diagram to determine the attributes position in each quadrant. Data collection is done by distributing questionnaires to customers in 7 (seven) regions who have consumed fish nuggets made by MBG. They are also interviewed and observed directly in their location. Those 7 regions are South Celebes, East Java, West Celebes, North Celebes, Central Celebes, Bali, and West Nusa Tenggara. The results show that the attributes that must be put in the high priority in regards to the product quality improvement are the expiration date, followed by the successive identity of the producer, the information about the product content, and the product coating materials.
\end{abstract}

Keywords: Priorities for Improvement, Gap Analysis, Product Quality, Melati Business Group, Cartesian Diagram

\section{Introduction}

Agroindustry is a field that has an important role in increasing the national income of Indonesia. Indonesia is a country that has abundant natural resources so that its utilization should get its own priority in development activities. The raw materials of agroindustry in the form of food crops and non-food products, fishery products, livestock and plantation are important capital to develop this country into a country that has sovereignty and food security, and has the power to compete in the business world. Food is the most essential basic need for human beings. Therefore, the 1945 Constitution has mandated that the State shall exercise food sovereignty (people's right to food) and strive for the fulfillment of food needs for the population.
In the Law No. 18 of 2012 on food chapter IV article 12 section 4 , mentioned that the implementation of food aims to improve welfare for farmers, fishermen, fish farmers, and food business. To achieve these objectives, the industry in the field of food becomes a priority in development. One of the important food in agroindustry is fish. Fishery products have advantages over other animal products because they contain high levels of protein, are easily digested, and contain unsaturated fats with very low cholesterol levels needed by the human body. Consequently, fish-based agroindustry needs to be developed, either in micro, small, medium, and large scale, whereas the application of research and technology results in the utilization of fishery resources can be expected to increase the added value of fishery products. 
One of the business groups that produce fish products is "Melati Business Group" in Makassar in the form of fish nugget. The scope of marketing area of this business group has not been widespread, so it is necessary to conduct research to develop its business potential. One way that can be pursued is to strive to improve the product quality, it is considered necessary to identify the priority of improving the quality of the fish nuggets. A product is said to be qualified if able to meet the characteristics expected by the customers. This is in accordance with the previous research conducted by Setiawan and Japarianto (2012) [1] on the analysis of the food quality and brand image effect on buying decision of Ganep's Bakery in Solo (Central Java), as well as Susilowati and Osmond $(2013)^{[2]}$ conduct research in regards to the customer perception of food quality, service quality and price effect on customer purchasing decision in Loving Hut Surabaya (East Java). Similarly, a research regading product quality and advertisement appeal effect on buying interest of indomie product (case study on society in Bekasi, West Java) and indicates that product quality factors have positive and significant effect on buying interest (Aisyah, 2015) ${ }^{[3]}$. Practically, it is not feasible to have too many improvement priorities because it will not be worth the added value of the product, so it needs to set its top priority (Yayu and Tjare, 2017) [4].

The need for the development efforts in the business group is also due to the current government keeps putting the welfare of the people as a top priority in national development by developing people's economy. Although is still categorized as small scale industry, the Melati Business Group (MBG) has contributed to the agribusiness sector that became the leading sector in South Celebes, Indonesia. The specific objective of this study is to produce a policy plan to improve the quality of processed fish products of Melati Business Group. In general, the expected benefits of the study are to recognize how well the quality of fish nugget made by MBG, can identify the nugget fish quality attributes that have improvement priority, can improve the quality of fish nuggets in order to increase customer buying interest, as well as to increase the income and welfare of its group members.

\section{Literature Review}

The effect of product quality on customer purchase intention, customer satisfaction, customer loyalty, and competitive advantage has been studied by many researchers. Dunk [5], for example, found that product quality contributes to a firm's competitive advantage when the reliance on environmental management accounting is high. However, it fails to do so when the reliance on environmental management accounting is low. Dunk [5] conducted his research on 119 functional area managers of manufacturing organizations accross Australia listed in Kompass Australia. Likewise, Jahanshahi et al. ${ }^{[6]}$ who conducted their research on the customers of Indian Automotive Industry in India found out that there are high positive correlation between the constructs of costumer service and product quality with costumer satisfaction and loyalty. Similarly, Saleem et al. [7] found out that product perceive quality has significant effect on purchase intention with level of satisfaction. Their research has been conducted on 130 students Pakistan. The data collected in regards to the students perception about product quality prior purchasing the Dell laptop and how much they satisfy with the brand quality. Furthermore, Jakfar et al. ${ }^{[8]}$ believe that the perceived quality (on image, brand name, and advertising) is positively relate to the level of satisfaction. Jakfar et al [8] undertaken their study toward Malaysians of Kuching City who did purchase product during sales promotion. In contrast, Budiastari ${ }^{[9]}$ found that product quality does not effect to customer satisfaction, hence she suggested to put mediation variable between product quality and customer satisfaction for the future research. Budiastari undertaken her study on the customers of Holcim Beton in Jakarta.

\section{Research Method}

Type of this study is an applied research which aims to provide solutions to certain problems. The population in this research are all buyers that have consumed fish nuggets made by Melati Business Group. The buyers are widespread in all provinces in Indonesia (34 provinces). However, this study only focus on seven provinces that have top buyers number level. The questionnaires were distributed 20-25 copies for each province, so the total of questionnaire distributed to sevent provinces are 160 copies. Of 160 copies, $112(70 \%)$ were sent back, whereas $100(62.5 \%)$ were completely filled and eligble for future processing. Beside using questionnaires as the main tool, this study also used interview and observation to deeply analyze the problems faced by the group. Interview process was done by phone, whereas observation was conducted directly in Melati Business Group in Makassar, South Celebes. Furthermore, the study design consists of the following steps:

(1) Identifying the indicators of product quality. To ensure that the identified indicators are really suitable with fish nuggets, the study was conducted using a combination of models developed by (Potter, Norman, and Hotchkiss, 2013) [10]. Jones in Susilowati and Osmond (2013) [2], West, Wood, and Harger in Reynaldo and Santoso (2015) [11], and Kotler and Keller (2012) [12]. The dimension of the product quality indicators is shown in the Table 1 (See in the Appendix 1).

(2) Preparing the instrument to collect data using questionnaire to find out the importance level of each product quality indicator and questionnaire to measure performance level of each product quality indicator using answer choice as developed by Likert (Likert Scale).

(3) Determining the research sample based on the number of parameters used. The guidelines are 5-10 times the estimated number of parameters (Hair, Black, Babin, and Anderson (2010) [13], so the number of respondents is at least 50 people. This study obtained 100 respondents from 
sevent provinces: South Celebes, East Java, West Celebes, North Celebes, Central Celebes, Bali, and West Nusa Tenggara. The detail respondents based on their location is shown in the Table 2 (See in the Appendeix 2).

(4) Collecting data using questionnaires, interviews and observation techniques.

(5) Performing tabulation and data processing using SPSS software to generate frequency table for each product attribute.

(6) Analyzing data using Importance Performance Analysis (IPA) method with steps as the following: (a) measure the average score of importance level (b) measure the average score of product performance level.

(7) Identifying the product attributes that should be improved, accompanied by a priority order. This step is carried out by measuring the gap between interest scores and performance scores by counting difference using formula as the following:

Gap score = Average performance - Average score of interest (1)

(8) Mapping the prioritized products attributes that must be improved using Cartesian diagram, in order to formulate product quality improvement policy. Values that intersect perpendicular to the vertical and horizontal axis were obtained based on the average result of the importance and performance level for the overall attributes.

\section{Result and Discussion}

The data in this study is processed using descriptive statistical analysis, Importance Performance Analysis (IPA), and priority mapping method of product attribute improvement. The results of the data processing along with the discussion are described below.

\subsection{Measurement Level of Interest the Quality of Fish Processed Products (Fish Nuggets) for Customers}

Each attribute or quality dimension of the fish nuggets produced by Melati Business Goup has different level of importance according to the perception of each customer. Therefore, measurement of the importance rating of each dimension of product quality has been done, where the results are shown in the Table 3 (See in the Appendix 3).

An interest rate score is obtained by summing the frequency of each response with each Likert score of each response, then divided by the number of respondents. The four highest importance scores respectively are: the expiration date information is clearly written in the packages, the shape and the packaging materials, the flovours (taste), and the product content information.

\subsection{Measurement of Fish Nugget Performance Level}

The level of product performance or quality of a food product is where all food characteristics are acceptable or can fulfill customer expectations. Therefore the quality of the product can be measured from the customer satisfaction level on the product attributes. Table 4 shows how the level of product performance according to customers perceptions (See in the Appendix 4).

Table 4 shows that the highest satisfaction scores are: the taste attribute of the fish nugget with score 4.1, followed by its shape and size that fit to be consumed. In contrast, the lowest satisfaction scores are: the attribute of the producer identity with a satisfaction score of 1.9 , followed by information about the product, then the nugget fish coating materials.

\subsection{Identifing Priorities for Improvement (PFI) on the Fish Nugget Attributes}

To identify prioritized improvement of fish nugget attributes, a gap analysis must first be done. The gap analysis is shown in the Table 5 (See in the Appendix 5).

Based on the calculation of the gap in the Table 5, the high prioritized improvement of the fish nugget attribute is firstly, the product's expiration date information. Based on the interviews, the Melati Business Group members of have no knowledge to determine the expiration date of the product. Secondly is the identity of the producer at the packages, and thirdly is the information about the product content, and fourthly is the fish nugget coating material. Gap analysis yields a priority sequence for the improvement of product attributes, but it is not able to classify which attributes really should be prioritized, which ones to maintain and which no need to be improved. Therefor it is essential that mapping those attributes must be done using Cartesian diagram. The mapping results are described in the Figure 1 (See in the Appendix 6).

\subsection{Mapping Attributes of Fish Nugget That Must be Prioritized to be Improved}

1. Quadrant A shows that the attributes affect customer satisfaction, but the fish nugget producer have not been able to implement them properly, including: 1) nugget has a good coating material so it still has a good taste and shape when fried (X3); 2) information on the content of its products (content/composition of materials, weight, etc.) (X7); 3) the packaging has the identity of the producer (X8); 4) product expiration date information (X10).

2. Quadrant B shows that the attributes affect customer satisfaction, where the Melati Business members have been implemented in accordance with the expectation of the fish nugget, including: 1) the flavor of the fish nugget $(\mathrm{X} 1) ; 2)$ the texture of the fish nugget (the right softness, not hard) (X2);3) the durablility of fish nugget, has a long enough life as stock for consumption (X6); 4) packaging that can guarantee product hygiene (shape and packaging materials) (X9).

3. Quadrant $\mathrm{C}$ shows that the attributes in this quadrant are not considered important by the fish nugget customers, while the quality provided by the Melati Business Group members quite mediocre. Based on the results in the Cartesian Diagram, no attributes exist in this 
quadrant.

4. Quadrant $\mathrm{D}$ indicates that the attributes in this quadrant are considered less important by the customers, but the quality of the products provided by Melati Business Group is excessive, including: 1) nuggets have an interesting shape that can affect the appetite to eat (X4); and 2) the size of each fish nugget is appropriate to be consumed (X5).

Based on the results of this research, Cartesian diagram shows some attributes of the fish nugget can affect customers satisfaction. When connected to the ten dimensions, namely: flavor (taste), texture, shape, size, durability, product information, packaging, and expiration information used in measuring the gap between the quality of the fish nugget and the expected quality of the fish nugget, can be explained as follows:

(1) Flavor Variable (X1) to Customer Satisfaction Variable (Y)

Based on the Interest-Satisfaction Analysis in Cartesian diagram, it show that the product quality attribute, especially for Flavor Variable (X1) is in quadrant B, which means that there has been a match between what is expected and what is perceived by customers on the fish nugget quality processed made by Melati Business Group.

(2) Texture Variable (X2) to Customer Satisfaction Variable (Y)

The results show that from the Analysis of InterestsSatisfaction in Cartesian diagram, it indicates that the fish nugget quality attribute, especially for Texture Variable (X2) is in Quadrant B. This means that there has been a match between what is expected and what is perceived by fish nugget customers produced by Melati Business Group.

(3) Coating Products Variable (X3) to Customer Satisfaction Variable (Y)

Research shows that from the Analysis of InterestsSatisfaction in Cartesian diagram, it indicates that the product quality attribute for Product Coating Variable (X3) is in Quadrant A. This means that according to the customers, fish nuggets have good coating material and is a an important factor and is expected, but Melati Business Group has not been able to provide the fish nugget quality in accordance with the desired.

(4) Shape Variable (X4) to Customer Satisfaction Variable (Y)

The results showed that from the Interests-Satisfaction Analysis in Cartesian diagram shows that the product quality attribute for Form Variable (X4) is in Quadrant D. This means that Melati Business Group has produced nugget which has an attractive shape, so that it can affect the appetite to eat, but considered less important by customers, so it is impressed excessive.

(5) Size Variable (X5) to Customer Satisfaction Variable (Y)

The results show that from the Analysis of InterestsSatisfaction in Cartesian diagram, indicates that product quality attribute for Size Variable (X5) lies in Quadrant D. This means that for attribute size of each nugget produced by
Melati Business Group has been appropriate or fit for consumption, but considered less important by customers, so it is impressed excessive.

(6) Endurance Variable (X6) to Customer Satisfaction Variable (Y)

The results show that from the Interests-Satisfaction Analysis which can also be seen in cartesian diagram, it shows that the product quality attribute for the Resistance Variable (X6) lies in Quadrant B. This means that for longlasting nugget attributes and have sufficient shelf life long as the supply for consumption is a thing that is expected by customers to be noticed by the Women's Group of Fishermen Wife "Fatimah Azzahra". In fact these attributes are felt very satisfactory by customers of processed fish products.

(7) Product Information Variable (X7) to Customer Satisfaction Variable (Y)

The result of the research shows that from the InterestsSatisfaction Analysis in Cartesian diagram, it shows that product quality attribute for Product Information Variable (X7) lies in Quadrant A. This means that the attribute information about the content of the product, such as content or composition of materials, weight, etc., according to customers are important and are expected factors, but Melati Business Group has not been able to provide information in accordance with the customer desired.

(8) Packaging Identity Variable (X8) to Customer Satisfaction Variable (Y)

The result of the research shows that from the Analysis of Interests-Satisfaction in Cartesian diagram indicates that the product quality attribute for packaging Identity Variable (X8) lies in Quadrant A. This means that the packaging attribute is an important factor and is expected by customers, but Melati Business Group has not been able to provide products as customers desired.

(9) Package Variable (X9) to Customer Satisfaction Variable (Y)

The results show that the results of the Interests of Satisfaction Analysis in Cartesian diagram, it shows that the product quality attribute for Packaging Variable (X9) lies in Quadrant B. This means that packaging attributes that can guarantee product hygiene (shape and material packaging) is expected by customers that must be noticed by Melati Business Group. In fact, these attributes are felt very satisfying by customers.

(10) Variable of Information Expired (X10) on Customer Satisfaction Variable (Y)

The results show that from the Analysis of InterestsSatisfaction in Cartesian diagram, it indicates that product quality attribute for Expired Information Variable (X10) lies in Quadrant A. This means that for attribute of expiration date information is considered as an important factor by customers, but Melati Business Group has not been able to provide products in accordance with the customers desired.

\section{Conclusion}

Based on the results of the research and discussion, it can 
be concluded that the results of gap analysis and mapping using Cartesian diagram show that the first priority attributes that must be improved are the expiration date, then the successive identity of the producer, the information about the product content, and the product coating materials. Mapping results also show that the product attributes that need to be maintained and improved is the flavor, texture, shelf life of the product, and packaging materials. Finally, the member of Melati Business Group requires skills to determine the product's expiration period, the knowledge to create informative packaging to support its marketing, and the ability to improve product coating.

\section{Recommendation}

Based on the result and discussion, it is recommended that the manager of Melati Business Group should consider to put the expiration date, the identity of the producer, the information about the product content, and the product coating materials in the package. Also, it is necessary to maintaine and improve the flavor, texture, shelf life of the product, and packaging materials in gaining successful marketing strategy. Finally, the manager should also pay attention to his/her group members in developing or improving their skills regarding how to determine product expiration date, how to create informative package, and how to improve product coating.

\section{Appendix}

\section{Appendix 1}

Table 1. Dimensional quality of the fish nugget.

\begin{tabular}{ll}
\hline No. & Quality Indicators of Fish Nuggets \\
\hline 1 & Flavors of the fish nugget \\
2 & The texture of the fish nugget (the right softness, not hard) \\
3 & Fish nugget havs a good flour coating, so it has good taste and good shape when fried \\
4 & Nugget has an interesting shape that can affect the appetite to consume \\
5 & The size of each nugget is fit for consumption \\
6 & Nugget is durable, has a long shelf life as stock for consumption \\
7 & Information on the product contents is clear \\
8 & The producer identity is clearly written in the packages \\
9 & The packaging ensure the hygiene and health of the fish nugget (shapes and packaging materials) \\
10 & Product expiration date information is clearly written in the packages \\
\hline
\end{tabular}

\section{Appendix 2}

Table 2. Number of respondents.

\begin{tabular}{lll}
\hline No & Province & Number of respondents \\
\hline 1 & South Celebes & 19 \\
2 & East Java & 18 \\
3 & West Celebes & 16 \\
4 & North Celebes & 13 \\
5 & Central Celebes & 12 \\
6 & Bali & 12 \\
7 & West Nusa Tenggara & 10 \\
Total & & 100 \\
\hline
\end{tabular}

\section{Appendix 3}

Table 3. Respondents' responses on the interest levels of fish nugget attributes.

\begin{tabular}{|c|c|c|c|c|c|c|}
\hline \multirow[b]{2}{*}{ No } & \multirow[b]{2}{*}{ Attribute } & \multicolumn{5}{|c|}{ Buyers' Response } \\
\hline & & $\begin{array}{l}\text { Not } \\
\text { important }\end{array}$ & $\begin{array}{l}\text { Not too } \\
\text { important }\end{array}$ & $\begin{array}{l}\text { Quite } \\
\text { important }\end{array}$ & Important & $\begin{array}{l}\text { Very } \\
\text { important }\end{array}$ \\
\hline 1 & Flavors of fish nuggets & 0 & 0 & 8 & 25 & 67 \\
\hline 2 & The texture of the fish nuggets (the right softness, not hard) & 0 & 0 & 15 & 29 & 56 \\
\hline 3 & Has a good flour coat so it stays has a good taste and shape when fried & 0 & 0 & 14 & 36 & 50 \\
\hline 4 & Nugget has an interesting shape that can affect the appetite to eat & 0 & 9 & 25 & 33 & 33 \\
\hline 5 & The size of each nugget is right for consumed & 0 & 11 & 33 & 27 & 29 \\
\hline 6 & Nugget is durable, has a shelf life long enough to be consumed & 0 & 5 & 7 & 35 & 53 \\
\hline 7 & Information on the content of the product (ingredients, weight, etc.) & 0 & 0 & 6 & 36 & 58 \\
\hline 8 & Packaging that has the identity of the producer & 0 & 4 & 7 & 38 & 51 \\
\hline 9 & $\begin{array}{l}\text { Packaging that can ensure cleanliness and health products (shapes and } \\
\text { packaging materials) }\end{array}$ & 0 & 0 & 3 & 27 & 70 \\
\hline 10 & Product expiration date information & 0 & 0 & 2 & 24 & 74 \\
\hline
\end{tabular}


Table 3. Continued.

\begin{tabular}{lllll}
\hline No & Attribute & Number of frequencies & Total Score & Interest score \\
\hline 1 & Flavors of fish nuggets & 100 & 459 & 4.59 \\
2 & The texture of the fish nuggets (the right softness, not hard) & 100 & 441 & 4.41 \\
3 & Has a good flour coat so it stays has a good taste and shape when fried & 100 & 436 & 4.36 \\
4 & Nugget has an interesting shape that can affect the appetite to eat & 100 & 390 & 3.90 \\
5 & The size of each nugget is right for consumed & 100 & 374 & 3.74 \\
6 & Nugget is durable, has a shelf life long enough to be consumed & 100 & 436 & 4.36 \\
7 & Information on the content of the product (ingredients, weight, etc.) & 100 & 452 & 4.52 \\
8 & Packaging that has the identity of the producer & 100 & 436 & 4.36 \\
9 & Packaging that can ensure cleanliness and health products (shapes and & 100 & 467 & 4.67 \\
10 & packaging materials) & 100 & 472 & 4.72 \\
\hline
\end{tabular}

\section{Appendix 4}

Table 4. Respondents response on the fish nugget performance level.

\begin{tabular}{|c|c|c|c|c|c|c|}
\hline \multirow[b]{2}{*}{ No } & \multirow[b]{2}{*}{ Attribute } & \multicolumn{5}{|c|}{ Buyers' Response } \\
\hline & & $\begin{array}{l}\text { Not } \\
\text { satisfied }\end{array}$ & $\begin{array}{l}\text { Less } \\
\text { satisfied }\end{array}$ & $\begin{array}{l}\text { Quite } \\
\text { satisfied }\end{array}$ & Satisfied & $\begin{array}{l}\text { Very } \\
\text { satisfied }\end{array}$ \\
\hline 1 & Flavors of fish nuggets & 0 & 8 & 19 & 28 & 45 \\
\hline 2 & The texture of the fish nuggets (the right softness, not hard) & 1 & 30 & 29 & 15 & 25 \\
\hline 3 & Has a good flour coat so it stays has a good taste and shape when fried & 16 & 28 & 23 & 18 & 15 \\
\hline 4 & Nugget has an interesting shape that can affect the appetite to eat & 9 & 21 & 25 & 25 & 20 \\
\hline 5 & The size of each nugget is fit for consumption & 6 & 25 & 30 & 20 & 19 \\
\hline 6 & Nugget is durable, has a long shelf life as stock for consumption & 14 & 23 & 20 & 23 & 20 \\
\hline 7 & Information on the contents of the product (material composition, weight, etc.) & 40 & 30 & 14 & 8 & 8 \\
\hline 8 & Packaging that has the identity of the nuggets product maker & 50 & 29 & 8 & 7 & 6 \\
\hline 9 & $\begin{array}{l}\text { Packaging that can ensure the hygiene and health of the product (shapes and } \\
\text { packaging materials) }\end{array}$ & 18 & 17 & 15 & 30 & 20 \\
\hline 10 & Product expiration date information & 50 & 20 & 12 & 11 & 7 \\
\hline
\end{tabular}

Table 4. Continued.

\begin{tabular}{lllll}
\hline No & Attribute & Number of frequencies & Total Score & Interest score \\
\hline 1 & Flavors of fish nuggets & 100 & 410 & 4.10 \\
2 & The texture of the fish nuggets (the right softness, not hard) & 100 & 333 & 3.33 \\
3 & Has a good flour coat so it stays has a good taste and shape when fried & 100 & 288 & 2.88 \\
4 & Nugget has an interesting shape that can affect the appetite to eat & 100 & 326 & 3.26 \\
5 & The size of each nugget is fit for consumption & 100 & 321 & 3.21 \\
6 & Nugget is durable, has a long shelf life as stock for consumption & 100 & 312 & 3.12 \\
7 & Information on the contents of the product (material composition, weight, etc.) & 100 & 190 & 1.14 \\
8 & Packaging that has the identity of the nuggets product maker & 100 & 317 & 3.17 \\
9 & Packaging that can ensure the hygiene and health of the product (shapes and & 100 & 205 & 2.05 \\
10 & packaging materials) & 100 & & \\
\hline
\end{tabular}

\section{Appendix 5}

Table 5. Gap between level of product performance and level of interest.

\begin{tabular}{|c|c|c|c|c|}
\hline No & Attribute & Product Performance & Interests & Gap \\
\hline 1 & Flavors of fish nuggets & 4.1 & 4.59 & -0.49 \\
\hline 2 & The texture of the fish nuggets (the right softness, not hard) & 3.33 & 4.41 & -1.08 \\
\hline 3 & Has a good flour coat so it stays has a good taste and shape when fried & 2.88 & 4.36 & -1.48 \\
\hline 4 & Nugget has an interesting shape that can affect the appetite to eat & 3.26 & 3.9 & -0.64 \\
\hline 5 & The size of each nugget is fit for consumption & 3.21 & 3.74 & -0.53 \\
\hline 6 & Nugget is durable, has a long shelf life as stock for consumption & 3.12 & 4.36 & -1.24 \\
\hline 7 & Information on the contents of the product (material composition, weight, etc.) & 2.14 & 4.52 & -2.38 \\
\hline 8 & Packaging that has the identity of the nuggets product maker & 1.9 & 4.36 & -2.46 \\
\hline 9 & $\begin{array}{l}\text { Packaging that can ensure the hygiene and health of the product (shapes and packaging } \\
\text { materials) }\end{array}$ & 3.17 & 4.67 & -1.5 \\
\hline 10 & Product expiration date information & 2.05 & 4.72 & -2.67 \\
\hline
\end{tabular}




\section{Appendix 6}

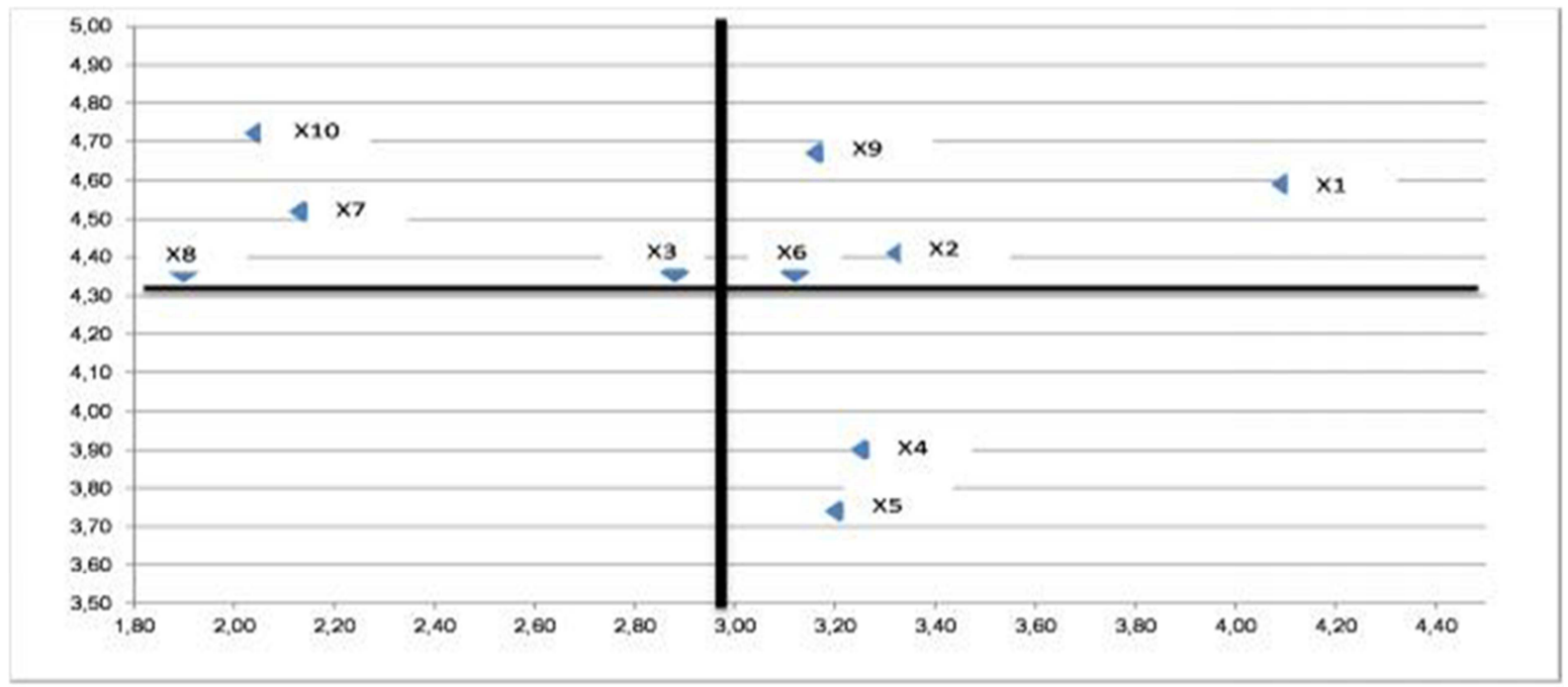

Figure 1. Cartesian diagram of fish nugget dimensionsional quality produced by melati bussiness group.

\section{References}

[1] Setiawan, Margaretha, F., and Japarianto, Edwin. 2012. Analysis of Effect of Food Quality and Brand Image on Decision of Purchase of Ganep's Bakery Bread in Solo City. Journal of Marketing Management. Vol. 1, No. 1.

[2] Susilowati, S, and Osmond, J. 2013. The Effect of Customer Perception on Food Quality, Quality of Service, and Price on Customer Purchase Decision in Loving Hut Surabaya. Journal of Hospitality and Management.

[3] Aisyah, Nurul. 2015. The Influence of Product Quality, Ad Interest on Interest Buying Indomie Products (Case Study In Society in Bekasi), Vol. 3, No. December 2, 2015.

[4] Yayu Meiniza Z., and Tjare A. Tjambolang. 2017. Identifying Product Quality Improvement Priority (Study Case in Women Group of Fishery "Fatimah Azzahra" Pattingaloang District, Makassar City, Indonesia.

[5] Dunk, A. S. 2007. Assessing the Effects of Product Quality and Environmental Management Accounting on the Competitive Advantage of Firms. Australasian Accounting Business and Finance Journal. Vol. 1, Issue 1, 2007, pp. 26-38.

[6] Jahanshahi, A. A., Gashti, M. A. H., Mirdamadi, S. A., Nawaser, K., and Khaksar, S. M. S. 2011. Study the Effects of Customer Service and Product Quality on Customer Satisfaction and Loyalty. International Journal of Humanities and Social Science. Vol. 1, No. 7 (Special Issue-June 2011), pp. 253-260.
[7] Saleem, A., Ghafar, A., Yousuf, M. I. M., and Ahmed, N. 2015. Product Perceived Quality and Purchase Intention with Consumer Satisfaction. Global Journal of Management and Business Research: E-Marketing. Vol. 15, Issue 1 Version 1. 0, 2015.

[8] Jakfar, S., Sze Na, A. G., Johari, A., and Myint, K. T. 2012. Examining the Product Quality Attributes That Influences Customer Satisfaction Most When the Price Was Discounted: A Case Study in Kuching Sarawak. International Journal of Business and Social Science. Vol. 3, No. 23, December 2012, pp. 221-236.

[9] Budiastari, S. 2016. The Influence of Product Quality, Price Perception and Brand Image on Satisfaction and Customer Loyalty Holcim Concrete Readymix In Jakarta. Jurnal Riset Manajemen Sains Indonesia (JRMSI). Vol 7, No. 2, 2016, pp. 345-362.

[10] Potter, N. Norman and Hotchkiss, J. H. 2013. Food Science. Fifth Edition. New York: Springer Science and Business Media.

[11] Reynaldo, Yovan, and Santoso, O. R. 2015. Analysis of Service Quality Impact and Product Quality to Customer Loyalty de'Excelso Surabaya Town Square. Journal of Hospitality and Service Management, Vol. 2.

[12] Kotler, Philip and Keller, Kevin Lane. 2012. Marketing Management. 14th edition. New York: Prentice Hall Publisher.

[13] Hair, J., Black, W., Babin, B., dan Anderson, R. (2010). Multivariate Data Analysis: A Global Perspective (7th edition), New Jersey: Pearson. 